\title{
Technology Enhanced Learning Solution for School Education in Oman
}

\author{
Maha Marhoon Mahamed Al Wahaibia ${ }^{\mathrm{a}}$, Vikas Rao Naidu ${ }^{\mathrm{a}}$, Prakash Kumar Udupi ${ }^{\mathrm{a}}$
}

E-learning is one of the major applications of Multimedia in Education. Lots of research has been taken place to find out the best possible solution which is simple and convenient to implement in the education system. This research paper analyses the importance of designing and implementing e-learning solution for school education in Oman. The outcome will suggest a project which will be about converting the traditional education at School to technological education by using LiveCode Community 7.1.3 which is a free open source software. In this research paper, we will focus on various e-learning solutions apart from educational games and we will discuss, why it is important to enhance the learning experience especially in school education of Oman.

Keywords: Multimedia, free and open source software, Unified Modeling, Livecode, E-learning

\section{Introduction}

Students need e-learning education games in different schools. The primary schools need efforts to development of education materials to make the study more enjoyable. One of the schools in Oman, Al Hathara School is still using traditional methods for educational materials like old conventional teaching. Through the outcome of this research we will be able to propose the application to development the educational games. This will change the methods adopted in school education more enjoyable and useful. The outcome of this research will be able to suggest a better E-learning education. This will enhance the teaching and learning process at school and help students who have difficulty in learning as well. Videos are useful for school students for better understanding of some difficult topics. In this research based project, authors will use live code, Adobe Photoshop, Illustrator and other graphic design tools. The suggested set of games will contain animated lessons. Also, the teacher will provide special activities for students related to each lesson. For flexible delivery of information and the introduction of fun with education, the e-learning will contain educational games. This research aims to increase the performance of a student in the classroom. Including that, interesting ways to increase their interaction with the teacher and make them more motivated in classroom and facilitate active learning environment in the class.

\section{System Study}

The current system is the traditional conversion method of education in schools, which rely on conservation preserving technological education, in the new system, Curriculum is transferred to ensure student visibility Hear and try one theme at a time. This helps the student to better understand and participate while learning.

To meet the need for educational resources and elearning, the interactive e-learning design was explored using (for free and open source software) using Livecode. Interactive E-learning will include some lessons in math animation Subject, educational videos also activities for students to find out if they understand the lesson. In addition to Students will also have fun with education through
Educational games. The interface is easy and portable between different computers, the teacher will be Able to view the application through visual displays. In order to increase students' interaction in Lessons in mathematics, e-learning can replace there are traditional books because e-learning will Change teaching methods by adding electronic multimediabased presentations. Interface must all warehouses are available at any time, moreover it is easy use.

\section{Proposed System}

The proposed system aims to transform traditional education at Al-hathara school at the pilot stage, which enabled the technology to use various multimedia programs. Later this research based application could be extended to other schools in Oman. E-learning will contain animation lessons, and will contain each lesson video tutorial. Moreover, the teacher to provide special activities for students related to each lesson. Flexible to provide information and the introduction of fun with education, the interface will also contain educational games. So, the purpose of the design is

- Design and development of interactive knowledge bank using all the skills in the field of multimedia.

- To achieve the highest of experience, knowledge and skill level.

- Expansion using open sources to get a new program strong.

- Identify the educational needs of students.

- Increase communication with faculty and outsourcing other people from outside the college sources faculty members

\section{Data Analysis}

The questionnaire as a tool used for gathering information from users. During the study period, the electronic questionnaire was distributed to 9 teachers, to get their opinion about the proposed system. The study results are analyzed and presented in the figures below.

This chart shows the use of the educational game in education. The most people select strongly agree but $31.58 \%$ select agree. The project of E-learning game is useful for a student to use the games in class to understand the subject perfect in below in figure 1 . 


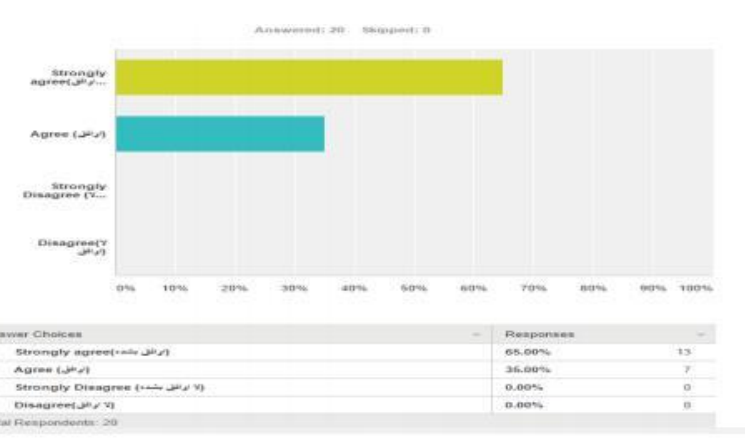

Fig 1: Opinion on Technology in Education
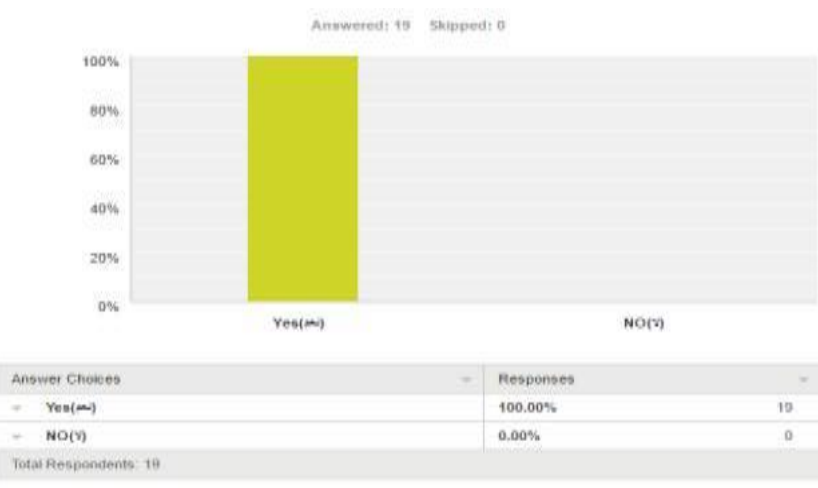

Figure 2: Opinion on Technology in Education

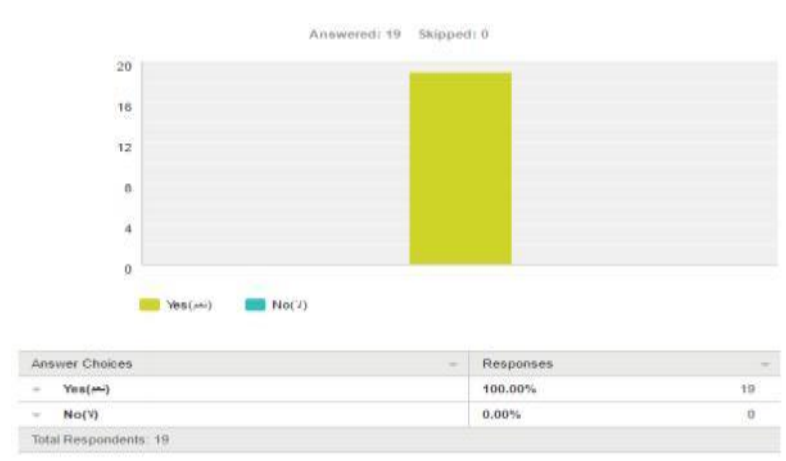

Figure 3: Opinion contents

This chart shows the use of educational games increases the students' motivations. All people select yes. That means the games help all students and motivate them to study in below in figure 2 .

This chart shows the use of educational games which impact of education remains for a longer period. All people select Yes. That means the learning games are impacting to remains to a longer time in below in figure 3 .

\section{System Design}

Following figure shows the flow of the initial design of the entire system.

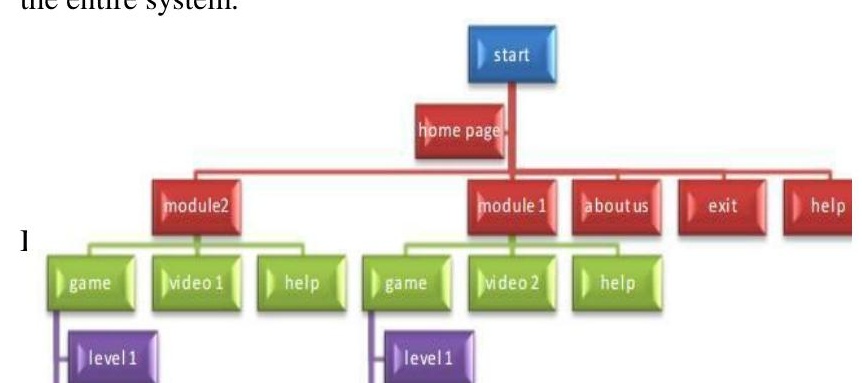

Figure 4: System Block diagram

The interface helps the user to navigate through the various elearning contents. User interaction with the system as shown below in Figure.

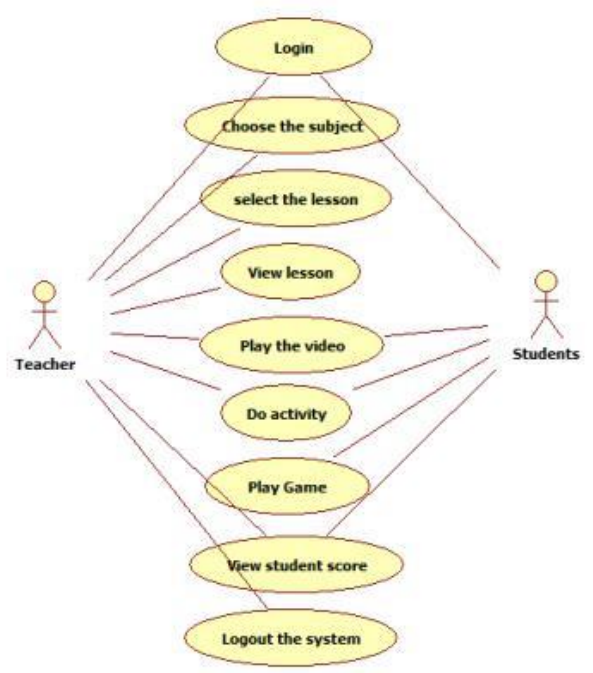

Figure 5: UML diagram

The description of the user's interaction with the system using standardized charts typical. Then describe the sequence of activities for the interaction of the teacher the teacher as shown in Figure 6.

This series of students - the teacher with activities in Systems have been defined using the activity scheme during the System design time.

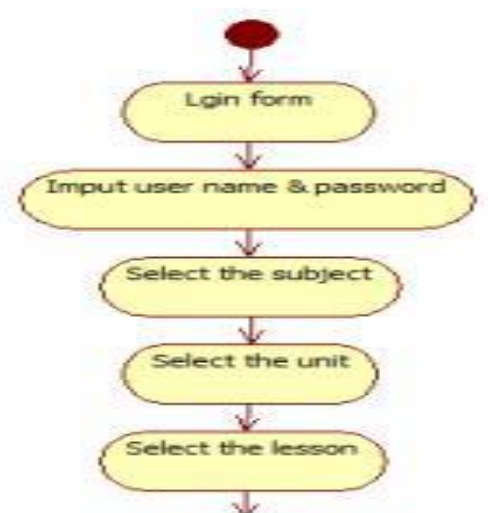


Figure6: Activity Diagram for teachers

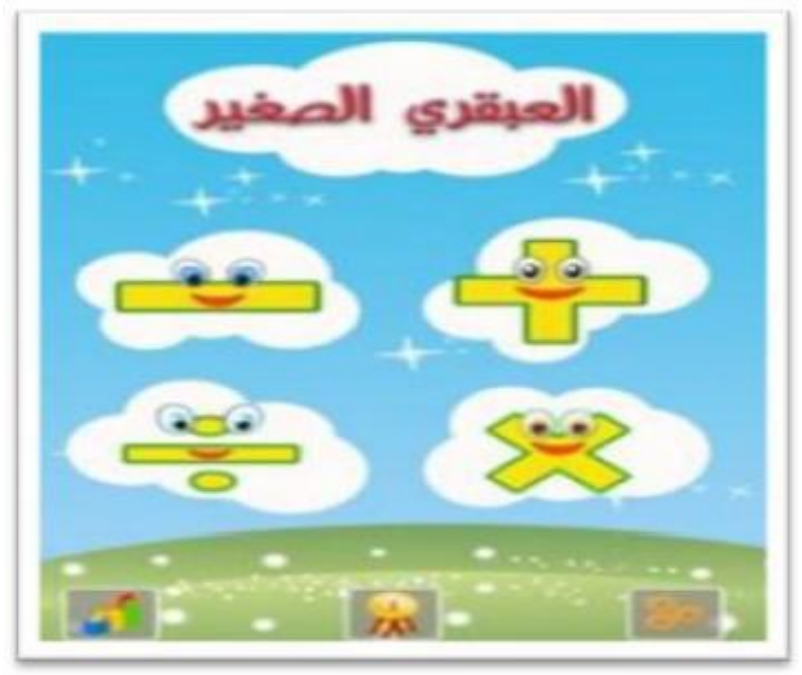

Figure 7: Prototype-1

Once prototypes are designed, the design of the final system starts with the creation of the authentication screen as shown in Figure 7.

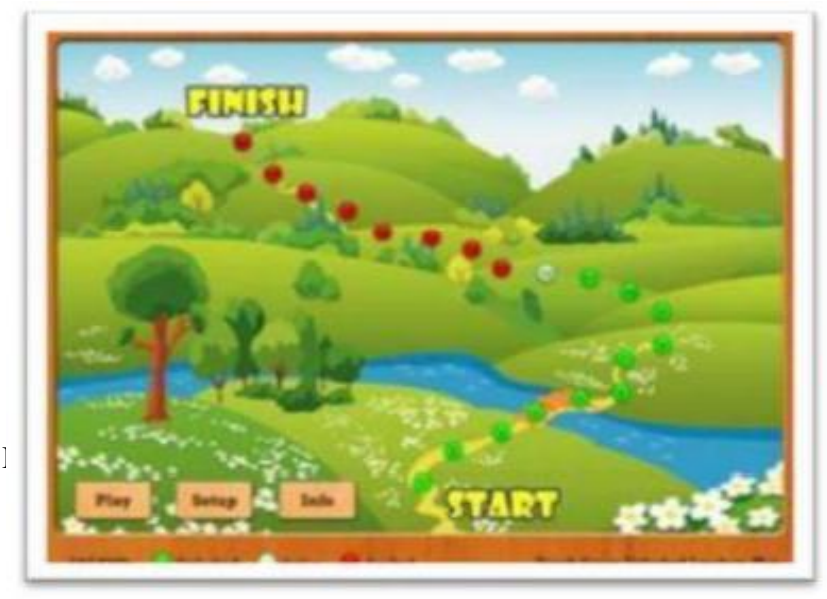

Figure 8: prototype 2

The user interface also directs the user to go through selective contents as shown in Figure 8.

\section{Conclusion}

The research attempted to transform the traditional method of teaching in stuttering schools to teach technology using interactive e-learning methods. The system specifically targets the subject of science, because in science subjects one needs to teach experts and view the contents of the material at the same time. This will help students understand subjects better. The application is designed to provide interactive elessons with sounds and effects. In addition, educational videos and integrated multimedia components for each lesson add value additions. Further enhanced content by incorporating games and activities provides students with analytical skills. The use of live code to develop interactive elearning and educational games ensures to expand content in the most cost-effective ethics.

\section{References}

[1] Sudhir (2010) what are the main types of feasibility study? Available at: http://www.indiastudychannel.com/experts/1958 7-What-AreThe-Main-Types-OfFeasibility-Study.aspx

[2] Utian, D. (2014) Dean's director tutorials - shockwave, animation, lingo, 3D. Available at: http://www.deansdirectortutorials.com

[3] Dix, A., Finlay, J.E. and Abowd, G. (1993) Humancomputer interaction. New York: Prentice Hall.

[4] Weinmann, E. and Lourekas, P. (2012) Photoshop CS5 for windows and Macintosh: Visual QuickStart guide. Berkeley, CA: Peachpit Press Publications.

[5] Elson-cook, M, 2001 principles of interactive Multimedia, U.K, McGraw Hill.

[6] ISTQB exam certification (no date) Available at: http://istqbexamcertification.com/what-is-spiralmodel-advantages-disadvantagesand-when-to-use-it/ (Accessed: 6 January 2017).

[7] Posted and Rouse, M. (2015) What is communication plan? - Definition from WhatIs.Com. Available at: http://whatis.techtarget.com/definition/communi cation-plan (Accessed: 6 January 2017).

[8] Sudhir (2010) what are the main types of feasibility study? Available at: http://www.indiastudychannel.com/experts/1958 7-What-AreThe-Main-Types-OfFeasibility-Study.aspx (Accessed: 11 January 2017).

[9] Posted and Rouse, M. (2007) what is spiral model (spiral lifecycle model)? - Definition fromWhatIs.Com. Available at: 
http://searchsoftwarequality.techtarget.com/defi nition/spiralmodel (Accessed: 11 January 2017). 